\title{
PENERAPAN MODEL PEMBELAJARAN ARIAS UNTUK MENINGKATKAN PRESTASI BELAJAR PESERTA DIDIK PADA POKOK BAHASAN KESETIMBANGAN KIMIA
}

\author{
Rezi Refita *, Herdini Herdini, Abdullah Abdullah
}

Program Studi Pendidikan Kimia, Fakultas Keguruan dan Ilmu Pendidikan Universitas Riau, Kampus Binawidya KM 12,5, Pekanbaru 28293, Riau, Indonesia.

\begin{tabular}{l}
\multicolumn{1}{c}{ Informasi Artikel } \\
\hline Sejarah Artikel: \\
Diterima: 11-07-2019 \\
Disetujui : 05-01-2021 \\
Dipublikasikan: 27-01-2021 \\
\hline Keywords: \\
ARIAS learning model, \\
learning achievement, \\
balance chemical, \\
\end{tabular}

\begin{abstract}
A b s t r a k
Penelitian ini bertujuan untuk mengetahui peningkatan prestasi belajar peserta didik dengan penerapan model pembelajaran ARIAS (Assurance, Relevance, Interest, Assessment, Satisfaction) pada pokok bahasan kesetimbangan kimia di kelas XI MIA SMAN 4 Pekanbaru. Jenis penelitian adalah penelitian eksperimen yang rancangan penelitiannya yaitu randomized control group pretest-posttest. Populasi terdiri dari 3 kelas dan sampel terdiri dari 2 kelas yaitu kelas XI MIA 5 sebagai kelas eksperimen dan kelas XI MIA 4 sebagai kelas kontrol yang dipilih secara acak setelah dilakukan uji homogenitas. Kelas eksperimen diterapkan model pembelajaran ARIAS sedangkan kelas kontrol tidak diterapkan model pembelajaran ARIAS. Pengujian hipotesis menggunakan uji-t pihak kanan, berdasarkan hasil analisis data diperoleh $t_{\text {hitung }}>t_{\text {tabel }}$ yaitu 6.04>1,67 artinya penerapan model pembelajaran ARIAS dapat meningkatkan prestasi belajar peserta didik pada pokok bahasan Keseimbangan Kimia di kelas XI MIA SMAN 4Pekanbaru.
\end{abstract}

\begin{abstract}
A b s t r a c t
This research aims to increase students learning achievement by implementation of ARIAS learning model on the balanced chemical subject in the class XI MIA SMAN 4Pekanbaru. The type of research is experimental research with randomized control group pretest-posttest design. The population consisted of 3 classes and the sample consisted of 2 classes, namely the XI MIA 5 class as the experimental class and the X MIA 4 class as the control class chosen randomly after homogeneity test. The experimental class is applied to the ARIAS learning model, while the control class does not apply the ARIAS learning model. Hypothesis testing uses the right-t-test, based on the results of data analysis obtained that $t$ count> $t$ table is 6.04> 1.67 meaning the implementation of ARIAS learning model can improve student learning achievement on the balanced chemical subject in the class XI MIA SMAN 4Pekanbaru.
\end{abstract}

(C) 2021 JPK UNRI. All rights reserved

\footnotetext{
*Alamat korespondensi:

e-mail: rezichemistry02@gmail.com

No. Telf: +6285365419167
} 


\section{PENDAHULUAN}

Belajar adalah suatu proses yang dilakukan seseorang untuk memperoleh sesuatu perubahan tingkah laku yang baru secara keseluruhan, sebagai hasil pengalamannya sendiri dalam interaksi dengan lingkungannya (Slameto, 2010). Proses pembelajaran merupakan suatu proses yang mengandung serangkaian perbuatan guru dan peserta didik atas dasar hubungan timbal balik yang berlangsung dalam situasi edukatif untuk mencapai tujuan tertentu, dalam proses tersebut terkandung multi peran guru (Rusman, 2012). Pembelajaran pada hakikatnya adalah kegiatan guru dalam membelajarkan siswa, yang berarti mengondisikan siswa belajar. Ada dua aspek penting yang terdapat dalam kegiatan pembelajaran. Aspek pertama hasil belajar, yakni perubahan perilaku pada diri siswa dan yang kedua proses belajar, yakni sejumlah pengalaman intelektual, emosional dan fisik pada diri siswa (Dimyati dan Mudjiono, 2006).

Peran guru dalam proses belajar mengajar adalah merancang proses pembelajaran, pengarah pembelajaran, pendidik, pembimbing, sebagai motivator, evaluator, serta fasilitator. Pentingnya peran guru dalam proses pembelajaran akan memberikan pengaruh hasil belajar. Oleh karena itu, guru dituntut perannya dalam proses belajar mengajar agar diperoleh hasil belajar yang maksimal. Hal ini dapat diwujudkan dengan menciptakan pembelajaran yang inovatif, kreatif dan produktif pada setiap mata pelajaran termasuk pelajaran kimia. Kimia merupakan salah satu dari sains yang mempelajari secara khusus materi, sifat, perubahan dan energi yang menyertai perubahannya. Sains berkaitan dengan cara mencari tahu dan memahami alam secara sistematis, sehingga sains bukan hanya penguasaan tentang kumpulan pengetahuan tetapi juga merupakan suatu proses penemuan (Budimansyah, 2003).

Hasil wawancara dengan salah seorang guru kimia kelas XI SMA Negeri 4 Pekanbaru, diperoleh informasi bahwa hasil belajar peserta didik pada pokok bahasan kesetimbangan kimia tahun ajaran 2017/2018 hanya 60\% peserta didik yang memenuhi Kriteria Ketuntasan Minimum (KKM) yang telah ditetapkan sekolah yaitu 75 . Rendahnya prestasi belajar peserta didik disebabkan oleh kurangnya kepercayaan diri peserta didik untuk berperan aktif dalam pembelajaran. Usaha yang telah dilakukan guru adalah dengan menerapkan metode diskusi untuk pengerjaan LKPD, namun tidak diiringi dengan model pembelajaran sehingga tidak banyak peserta didik yang terlibat aktif dalam pembelajaran. Kurangnya keaktifan peserta didik juga disebabkan oleh rendahnya minat belajar peserta didik, hal ini berdampak pada pemahaman peserta didik terhadap materi yang dipelajari.

Guru telah berupaya dengan menggunakan metode pembelajaran yang bervariasi seperti diskusi, tanya jawab dan ceramah. Namun pembelajaran yang dilakukan guru belum mampu mendorong peserta didik untuk aktif dalam pembelajaran. Kurangnya keaktifan peserta didik dalam belajar dapat disebabkan oleh banyak hal, salah satunya adalah kurangnya kepercayaan diri yang dimiliki oleh peserta didik. Menyikapi permasalahan tersebut, diperlukan model pembelajaran yang dapat meningkatkan kepercayaan diri peserta didik dengan menerapkan salah satu model pembelajaran yaitu model pembelajaran ARIAS.

Model pembelajaran ARIAS terdiri dari lima komponen yaitu Assurance (percaya diri), Relevance (relevansi), Interest (minat/perhatian), Assessment (penilaian/evaluasi)dan Satisfaction (penguatan). Makna urutan kelima komponen tersebut, yaitu penanaman rasa percaya diri pada peserta didik ditempatkan diurutan pertama. Rasa percaya diri ini menjadi prioritas utama yang harus dibangkitkan sejak awal oleh guru. Percaya diri dapat meningkatkan motivasi serta semangat belajar peserta didik. Pembelajaran yang dilaksanakan ada relevansinya dengan kehidupan siswa. Urutan ketiga, pembelajaran diusahakan menarik perhatian peserta didik. Keempat, mengevaluasi pembelajaran yang telah dilakukan serta yang terakhir yaitu menumbuhkan rasa bangga pada peserta didik dengan memberikan penguatan sehingga peserta didik merasa puas setelah melaksanakan pembelajaran (Rahman dan Amri, 2014). Beberapa penelitian yang telah mengembangkan 
pembelajaran berasis ARIAS. Lubis dan Purba, (2018) telah melaporkan model pembelajaran ARIAS untuk meningkatkan hasil belajara dan percaya diri peserta didik dan diterapka dalam materi kimia umum. Silvia et al (2016) juga mengembangkan model pembelajaran ARIAS untuk meningkatkan hasil belajar peserta didik dan ditemukan bahwa terdapat peningkatan hasil belajar peserta didik sebasar $60.5 \%$ dibandingkan dengan perlakuan.

Penelitian ini bertujuan untuk mengetahui apakah penerapan model pembelajaran ARIAS dapat meningkatkan prestasi belajar peserta didik pada pokok bahasan kesetimbangan kimia di kelas XI MIA SMA Negeri 4 Pekanbaru.

\section{METODE PENELITIAN}

Bentuk penelitian yang dilakukan adalah penelitian eksperimen dengan rancangan penelitian Randomized Control Group Pretest-Posttest yang dilakukan terhadap dua kelas. Kelas eksperimen diterapkan model pembelajaran ARIAS dan kelas kontrol tanpa model pembelajaran ARIAS. Penelitian dilaksanakan di kelas XI MIA SMAN 4 Pekanbaru semester ganjil tahun ajaran 2018/2019. Waktu pengambilan data dilakukan pada bulan Oktober sampai dengan Desember 2018. Populasi pada penelitian ini adalah peserta didik kelas XI MIA SMAN 4 Pekanbaru yang terdiri dari 3 kelas. Pengambilan sampel dilakukan dengan cara dilakukan uji homogenitas terlebih dahulu dari data yang telah terdistribusi normal pada seluruh populasi untuk memastikan seluruh kelas memiliki kemampuan yang sama. Kemudian dipilih secara acak dua kelas yang telah homogen untuk dijadikan sampel. Diperoleh kelas XI MIA 5 sebagai kelas eksperimen dan kelas XI MIA 4 sebagai kelas kontrol.

Data yang dikumpulkan diperoleh dari : (1) Data nilai ulangan materi sebelumnya yaitu materi laju reaksi untuk uji normalitas dan uji homogenitas sebagai data awal untuk menentukan kelas eksperimen dan kelas kontrol (2) Pretest, dilakukan pada kedua kelas sebelum masuk materi kesetimbangan kimia, dan (3) Posttest, dilakukan pada kedua kelas setelah selesai materi kesetimbangan kimia dan seluruh proses dilakukan. Teknik analisis data yang digunakan pada penelitian adalah uji-t, dilakukan setelah data di uji normalitasnya dengan menggunakan uji normalitas Liliefors. Data berdistribusi normal jika harga $\mathrm{L}_{\text {maks }}<\mathrm{L}_{\text {tabel }}$ dengan kriteria pengujian $(\alpha=0,05)$, harga $\mathrm{L}_{\text {tabel }}$ diperoleh dengan persamaan 1:

$$
L_{\text {tabel }}=\frac{0.886}{\sqrt{n}}
$$

Setelah data terdistribusi normal, kemudian dilakukan uji homogenitas dengan menguji varians kedua sampel (homogen atau tidak) terlebih dahulu, dengan persamaan 2 :

$$
F_{\text {hitung }}=\frac{S^{2}(\text { varians terbesar })}{S^{2}(\text { varians terkecil })}
$$

Kriteria pengujian adalah jika $\mathrm{F}_{\text {hitung }}<\mathrm{F}_{\text {tabel }}$, dimana $\mathrm{F}_{\text {tabel }}$ diperoleh dari daftar distribusi $\mathrm{F}$ dengan peluang $\alpha$, dimana $(\alpha=0,05)$ dengan $\mathrm{dk}=\left(\mathrm{n}_{1}--1, \mathrm{n}_{2}-1\right)$, maka kedua sampel dinyatakan memiliki varians yang sama atau homogen. Kemudian dilanjutkan dengan uji kesamaan rata-rata menggunakan uji $\mathrm{t}$ dua pihak untuk mengetahui kehomogenan kemampuan kedua sampel. Uji $\mathrm{t}$ ditunjukkan pada persamaan 3. Dengan $S g$ merupakan standar deviasi gabungan yang dapat dihitung dengan menggunakan persamaan 4 .

$$
\mathrm{t}=\frac{\overline{\mathrm{X}_{1}}-\overline{\mathrm{X}_{2}}}{\mathrm{Sg} \sqrt{\frac{1}{\mathrm{n}_{1}}+\frac{1}{\mathrm{n}_{2}}}}
$$




$$
\mathrm{Sg}=\sqrt{\frac{\left(\mathrm{n}_{1}-1\right) \mathrm{S}_{1}^{2}+\left(\mathrm{n}_{2}-1\right) \mathrm{S}_{2}^{2}}{\mathrm{n}_{1}+\mathrm{n}_{2}-2}}
$$

Kriteria pengujian adalah jika $t_{\text {hitung }}$ terletak antara $-t_{\text {tabel }}$ dan $t_{\text {tabel }}$ didapat dari daftar distribusi $t$ dengan $\mathrm{dk}=\mathrm{n}_{1}+\mathrm{n}_{2}-2$ dengan kriteria probabilitas $1-1 / 2 \alpha$ dengan $\alpha=0,05$ maka kedua sampel dikatakan homogen(Agus Irianto, 2010).

\section{HASIL DAN PEMBAHASAN}

\subsection{Uji Normalitas Data Nilai Awal}

Uji normalitas adalah ujiuntuk mengukur apakah data yang didapatkan memiliki distribusi normal atau tidak. Uji normalitas dilakukan pada data nilai awal, pretest, dan data posttest. Hasil uji normalitas data nilai awal dapat dilihat pada Tabel 1.

Tabel 1. Hasil analisis uji normalitas data nilai awal

\begin{tabular}{cccccccc}
\hline Data & Kelas & $\boldsymbol{N}$ & $\overline{\mathbf{X}}$ & $\mathbf{S}$ & $\mathbf{L}_{\text {maks }}$ & $\mathbf{L}_{\text {tabel }}$ & Keterangan \\
\hline \multirow{4}{*}{ Data nilai awal } & XI MIA 3 & 36 & 69,94 & 22,7093 & 0,0934 & 0,1477 & Berdistribusi Normal \\
& XI MIA 4 & 35 & 62,63 & 19,4967 & 0,0721 & 0,1498 & Berdistribusi Normal \\
\multirow{4}{*}{ Pretest } & XI MIA 5 & 34 & 56,26 & 21,3915 & 0,0678 & 0,1519 & Berdistribusi Normal \\
& XI MIA 4 & 35 & 26,4 & 8,2434 & 0,1104 & 0,1498 & Berdistribusi Normal \\
& XI MIA 5 & 34 & 30,47 & 10,3755 & 0,1148 & 0,1519 & Berdistribusi Normal \\
& XI MIA 4 & 35 & 61,77 & 22,5115 & 0,1281 & 0,1498 & Berdistribusi Normal \\
& XI MIA 5 & 34 & 89,47 & 5,8942 & 0,1406 & 0,1519 & Berdistribusi Normal \\
\hline
\end{tabular}

Keterangan; $N$ = jumlah data pada sampel, $\overline{\mathrm{X}}=$ nilai rata-rata sampel, $\mathrm{S}=$ simpangan baku, $\mathrm{L}_{\text {maks }}=$ nilai hitung Liliefors maksimum dan $\mathrm{L}_{\text {tabel }}=$ nilai tabel Liliefors

Terlihat pada Tabellbahwa semua sampelterdistribusi normal karena diperolehL $\mathrm{L}_{\text {maks }} \leq \mathrm{L}_{\text {tabel }}$ yang sesuai dengan ketentuan uji normalitaslilieforsbahwa untuk data yang terdistribusi normal $\mathrm{L}_{\text {maks }} \leq$ $\mathrm{L}_{\text {tabel. }}$.

\subsection{Uji Homogenitas}

Uji homogenitas adalah uji yang digunakan untuk melihat dua atau lebih kelompok data sampel memiliki varians dan kemampuan yang sama (homogen).Uji homogenitas dilakukan pada data nilai awal (nilai ulangan laju reaksi) yang berdistribusi normal. Data uji homogenitas dari data nilai awal disajikan pada Tabel 2.

Tabel 2. Hasil analisis uji homogenitas data nilai awal

\begin{tabular}{ccccccccc}
\hline Kelas & $\boldsymbol{N}$ & $\sum \boldsymbol{X}$ & $\overline{\mathbf{X}}$ & $\mathbf{F}_{\text {tabell }}$ & $\mathbf{F}_{\text {hitung }}$ & $\mathbf{T}_{\text {tabel }}$ & $\mathbf{T}_{\text {hitung }}$ & Keterangan \\
\hline XI MIA & 36 & 2618 & 69,9444 & & & & & \\
3dan & 35 & 2192 & 62,6286 & 1,80 & 1,36 & 2,00 & 1,77 & Homogen \\
XI MIA 4 & & & & & \\
XI MIA & 36 & 2618 & 69,9444 & & & & & \\
$\quad$ 3dan & 34 & 1913 & 56,2647 & 1,82 & 1,23 & 2,00 & 3,16 & Tidak Homogen \\
$\begin{array}{c}\text { XI MIA 5 } \\
\text { XI MIA 4 }\end{array}$ & 35 & 2192 & 62,6286 & & & & & \\
$\quad$ dan & 34 & 1913 & 56,2647 & & & & & \\
XI MIA 5 & & & & & & & & \\
\hline
\end{tabular}


Keterangan : $N=$ Jumlah data pada sampel, $\Sigma X=$ Jumlah nilaiawal seluruh peserta didik, $\overline{\mathrm{X}}=$ Rata-rata nilai awal peserta didik, $F_{\text {hitung }}=$ nilai hitung uji Fisher, $F_{\text {tabel }}=$ nilai tabel uji Fisher, $t_{\text {hitung }}=$ nilai hitung uji-t dan $\mathrm{t}_{\text {tabel }}=$ nilai tabel uji-t

Terlihat pada Tabel 3. bahwa terdapat dua pasang kelas yang memiliki kemampuan yang sama (homogen) yaitu pasangan kelas XI MIA 3 dengan kelas XI MIA 4 dan pasangan kelas XI MIA 4 dengan kelas XI MIA 5. Kemudian kedua pasang kelas yang homogen dipilih secara acak dengan mengundi kelas yang akan dijadikan kelas eksperimen dan kelas kontrol, ternyata diperoleh bahwa kelas XI MIA 5 sebagai kelas eksperimen dan kelas XI MIA 4 sebagai kelas kontrol.

\subsection{Uji Hipotesis}

Data yang digunakan untuk uji hipotesis dalam penelitian adalah selisih antara nilai pretest dan posttest. Selisih nilai tersebut menunjukkan besarnya nilai prestasi peserta didik dan sesudah belajarpokok bahasan kesetimbangan kimia dengan dan tanpa model pembelajaran ARIAS. Hasil analisis uji hipotesis dapat dilihat pada Tabel 3.

Tebel 3. Hasil analisis uji hipotesis

\begin{tabular}{cccccccc}
\hline Kelas & $\boldsymbol{N}$ & $\sum \boldsymbol{X}$ & $\overline{\mathbf{X}}$ & $\mathbf{S}_{\text {gah }}$ & $\mathbf{T}_{\text {tabel }}$ & thitung & Keterangan \\
\hline $\begin{array}{c}\text { Eksperimen } \\
\text { Kontrol }\end{array}$ & 34 & 1858 & 59 & 16,2518 & 1,67 & \multirow{2}{*}{6.04} & Hipotesis diterima \\
\hline
\end{tabular}

Catatan: $N=$ jumlah peserta didik yang menerima perlakuan, $\sum X=$ jumlah nilai selisih posttest dan pretest, $\overline{\mathbf{X}}=$ nilai rata-rata selisih posttest dan pretest dan $\mathrm{S}_{\mathrm{gab}}=$ standar deviasi gabungan .

Terlihat dari hasil yang terdapat pada Tabel 5. bahwa $t_{\text {hitung }}>t_{\text {tabelyang berarti bahwa } H_{1}}$ diterima, maka penerapan model pembelajaran ARIAS dapat meningkatkan prestasi belajar peserta didik pada pokok bahasan kesetimbangan kimia di kelas XI MIA SMA Negeri 4 Pekanbaru

Model pembelajaran ARIAS terdiri dari lima komponen yaitu Assurance (Percaya Diri), Relevance (sesuai dengan kehidupan peserta didik), Interest (Minat dan Perhatian Peserta Didik), Assessment (Evaluasi), Satisfaction (Penguatan). Assurance ataupun kepercayaan diri merupakan komponen model Pembelajaran ARIAS yang pertama. Assurance memiliki hubungan dengan sikap percaya, yakin akan berhasil atau yang berhubungan dengan harapan untuk berhasil. Tahap Assurance dilakukan pada kegiatan awal sebelum pembelajaran dimulai. Prayitno (dalam Sopah, 2008) menyatakan bahwa peserta didik yang memiliki sikap percaya diri dan memiliki penilaian positif tentang dirinya cenderung menampilkan prestasi yang baik secara terus menerus. Sikap percaya diri ini perlu ditanamkan kepada peserta didik untuk mendorong mereka agar berusaha dengan maksimal guna mencapai keberhasilan yang optimal.

Tahap assurance dimulai pada kegiatan awal, pada tahap assurance guru menampilkan video motivasi kepada peserta didik guna untuk menanamkan rasa percaya diri. Contohnya pada pertemuan pertama peserta didik diberi video motivasi inspirasi pagi oleh Merry Riana yang berisi tentang keharusan bersyukur kepada tuhan karena masih diberikan kesempatan untuk hidup dan menjalani hari ini. Dalam video ini peserta didik diberikan motivasi bahwa semua hal yang hebat sebenarnya sudah ada dalam diri peserta didik itu sendiri, mereka hanya perlu meyakinkan diri bahwa mereka dapat merubah hari ini menjadi lebih baik dari hari sebelumnya.

Tahap kedua dalam penerapan model pembelajaran ARIAS adalah tahap relevance. Tahap relevance berhubungan dengan kehidupan peserta didik baik berupa pengalaman sekarang maupun yang berhubungan dengan kebutuhan karier yang akan datang. Relevansi membuat peserta didik merasa kegiatan pembelajaran yang mereka ikuti memiliki nilai, manfaat, dan berguna bagi kehidupan mereka. Hal ini sesuai dengan pernyataan bahwa relevance merupakan tahapan pembelajaran kontekstual yang membantu peserta didik mengaitkan antara materi yang diajarkan dengan situasi 
dunia nyata dan mendorong peserta didik membuat hubungan antara pengetahuan yang dimiliki dengan penerapannya dalam kehidupan sehari-hari (Suprijono, 2011). Pada pertemuan pertama peserta didik diberikan pertanyaan, "pernahkah kalian membakar kertas? apakah pembakaran kertas merupakan reaksi kimia? apakah yang terjadi setelah kertas dibakar? Apakah abu hasil pembakaran kertas dapat berubah menjadi kertas kembali?" dari jawaban-jawaban yang diberikan peserta didik, guru akan mengaitkan dengan pelajaran yang akan dipelajari bahwa ternyata ada reaksi kimia yang bisa kembali lagi menjadi zat awal.

Pembelajaran dilanjutkan dengan cara menarik perhatian peserta didik dalam tahap Interest. Perlunya menciptakan suasana yang membuat peserta didik antusias terhadap persoalan yang ada dapat menarik minat mereka untuk memecahkan persoalannya. Seperti pada pertemuan pertama, antusiasme peserta didik dapat dibangkitkan dengan memberikan reward kepada peserta didik yang dapat menyelesaikan LKPD dan dapat mempresentasikan jawaban LKPD kelompoknya didepan kelas dengan baik. Pemberian hadiah ini akan meningkatkan jiwa kompetisi antar kelompok sehingga mereka antusias dalam menyelesaikan LKPD. Hal ini sesuai dengan pendapat Fatahillah (2013) yang menyatakan bahwa kompetisi antar kelompok membuat peserta didik lebih termotivasi menjadi lebih baik dari yang lainnya dan meningkatkan ketertarikan dalam pembelajaran masing-masih peserta didik. Untuk menanggapi hasil dari presentasi kelompok yang terpilih selanjutnya dilakukan tahap assessment.

Pada tahap assessment peserta didik diminta untuk mengevaluasi hasil diskusi kelompok penyaji. Selain mengevaluasi jawaban temannya, peserta didik juga dapat mengevaluasi jawaban mereka sendiri dengan membandingkan jawabannya dengan jawaban kelompok penyaji. Pada tahap assessment guru juga mengevaluasi jawaban peserta didik secara objektif dan adil serta menyampaikan hasil evaluasi kepada seluruh peserta didik. Sesuai dengan pendapat Fajaroh dan Dasna (2007) yang mengungkapkan bahwa assessment merupakan alat untuk mengetahui apakah yang telah diajarkan sudah dipahami oleh peserta didik, untuk memonitor kemajuan peserta didik sebagai individu maupun sebagai kelompok, untuk merekam apa yang telah dicapai peserta didik dan membantu peserta didik dalam belajar. Bagi peserta didik sendiri, evaluasi merupakan umpan balik tentang kelebihan dan kelemahan yang dimiliki, dapat mendorong belajar lebih baik dan meningkatkan motivasi berprestasi. Setelah melakukan evaluasi guru akan memberikan penguatan kepada seluruh peserta didik terhadap materi yang telah dipelajari dan memberikan penghargaan kepada kelompok penampil pada tahap satisfaction.

Satisfaction merupakan segala hal yang berhubungan dengan rasa bangga dan puas atas hasil yang dicapai. Dalam teori belajar satisfaction adalah reinforcemnet (penguatan). Setelah kelompok penampil menyampaikan hasil diskusi kelompok mereka, guru akan memberikan penghargaan seperti meminta peserta didik lainnya memberikan tepuk tangan atas presentasi yang telah dilakukan. Selain itu guru juga akan memberikan hadiah yang telah dijanjikan kepada peserta didik pada tahap interest. Setelah itu guru akan memberikan penguatan dengan menarik kesimpulan terhadap materi yang telah dipelajari yang melibatkan peserta didik. Penarikan kesimpulan dengan melibatkan peserta didik bertujuan untuk melatih daya ingat peserta didik sehingga materi yang telah diajarkan dapat bertahan lebih lama dalam memorinya.

Setiap tahapan dari model pembelajaran ARIAS memberikan pengaruh terhadap keaktifan peserta didik. Namun dari kelima tahapan yang ada, ada dua tahap yang sangat berpengaruh terhadap keaktifan belajar peserta didik yaitu tahap assurance dan tahap interest. Tahap assurance sangat berperan dalam menanamkan rasa percaya diri terhadap peserta didik, menanamkan rasa percaya diri pada tahap assurance dilakukan guru dengan memberikan video motivasi di awal pembelajaran. Penggunaan video motivasi untuk menanamkan rasa percaya diri pada diri peserta didik dilakukan karena video motivasi berisi kata-kata yang dapat membangkitkan semangat serta memberikan pengaruh positif bagi pendengarnya. Dengan adanya tahap assurance pada model pembelajaran ARIAS dapat disimpulkan bahwa peserta didik yang diajarkan dengan menggunakan model 
pembelajaran ARIAS memiliki rasa percaya diri yang lebih tinggi dibandingkan dengan peserta didik yang diajarkan dengan model pembelajaran konvensional.

Peran tahap interest dalam pembelajaran dapat meningkatkan minat belajar peserta didik. Tahap interest dilakukan sebelum peserta didik mengerjakan LKPD dengan memberikan penghargaan di akhir pembelajaran berupa hadiah yang telah disepakati. Pemberitahuan akan diberikan hadiah sengaja disampaikan sebelum pengerjaan LKPD agar peserta didik termotivasi untuk mengerjakan LKPD, dengan adanya hadiah di akhir pembelajaran membuat peserta didik bersemangat dan antusias ketika mencari, menemukan serta memecahkan permasalahan yang terdapat dalam LKPD sehingga pembelajaran menjadi bermakna dan bisa bertahan lebih lama di dalam memori peserta didik sehingga terjadi peningkatan prestasi peserta didik.

\section{KESIMPULAN}

\subsection{Kesimpulan}

Berdasarkan hasil perolehan dan pengolahan data dapat disimpulkan bahwa "Penerapan model pembelajaran ARIAS (Assurance, Relevance, Interest, Assessment, Satisfaction) dapat meningkatkan prestasi belajar peserta didik pada pokok bahasan kesetimbangan kimia di kelas XI MIA SMAN 4 Pekanbaru".

\subsection{Rekomendasi}

Berdasarkan kesimpulan yang diperoleh, peneliti merekomendasikan model pembelajaran ARIAS dapat dijadikan sebagai salah satu alternatif model pembelajaran kimia khususnya pada pokok bahasan kesetimbangan kimia yang dapat meningkatkan prestasi belajar peserta didik.

\section{DAFTAR PUSTAKA}

Irianto, A. 2010. Statistika Konsep Dasar dan Aplikasi. Kencana. Jakarta

Suprijono, A. 2011. Cooperative Learning Teori dan Aplikasi Paikem. Pustaka Pelajar. Yogyakarta Budimansyah, D. 2003. Model Pembelajaran Berbasis Portofolio. PT Genesindo. Bandung Dimyati, Mudjiono. 2006. Belajar dan Pembelajaran. Rineka Cipta. Jakarta.

Fajaroh, F. Dasna, I.W. 2007. Penggunaan Model Pembelajaran Learning Cycle untuk Meningkatkan Motivasi Belajar dan Hasil Belajar Kimia Zat Aditif dalam Bahan Makanan Pada Siswa Kelas II SMU Negeri 1 Tumpang Malang. Jurnal Pendidikan dan Pembelajaran. 11(2): 112-122.

Lubis, A., Purba, A. 2018. Model pembelajaran arias dengan master learning dalam meningkatkan hasil belajar dan kepercayaan diri belajar kimia umum. Jurnal Penelitian Pendidikan MIPA. 3(1): 179-185

Nazir, M. 2010. Metode Penelitian. Penerbit Graha Indonesia. Jakarta

Rahman, M., Amri, S. 2014. Model Pembelajaran ARIAS Terintegratif dalam Teori dan Praktik untuk Menunjang Penerapan Kurikulum 2013. Prestasi Pustaka Publisher. Jakarta

Rusman. 2012. Model-Model Pembelajaran Mengembangkan Profesionalisme Guru Edisi Kedua. PT. Raja Grafindo Persada. Jakarta.

Silvia, A., Sanjaya, Anom, K. 2016. Penerapan model pembelajaran assurance, relevance, interest, assessment, and satisfaction (arias) untuk meningkatkan hasil belajar siswa pada mata pelajaran kimia kelas XI MIA 3 SMA Negeri 10 Palembang. Jurnal Penelitian Pendidikan Kimia, 3(1): 49-61

Slameto. 2010. Belajar dan Faktor yang Mempengaruhinya. Rineka Cipta. Jakarta. 